\title{
O PROCESSO DE ACONSELHAMENTO EM DST, HIV E AIDS E SUA INTER-RELAÇÃO COM OS PADRÕES DE CONHECIMENTO DA ENFERMAGEM - UMA CONEXÃO
}

[The counseling process in STD, HIV and AIDS as well as its interrelationship with nursing knowledge patterns - a connection]

\author{
Maria Rita C.B. Almeida* \\ Liliana Maria Labronici**

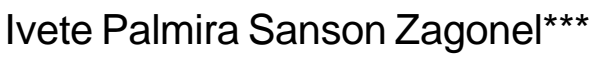

RESUMO: Artigo de reflexão que tem como objetivo inter-relacionar a prática do processo de aconselhamento aos quatro padrões de conhecimento da Enfermagem, o empírico, estético, pessoal e ético propostos por CARPER (1978) O processo de aconselhamento em DST, HIV e AIDS compreende uma relação de ajuda e cuidado para com o outro, com a finalidade de resgatar a integralidade da pessoa, descobrir suas potencialidades, fortalecer sua autonomia e responsabilidade no desenvolvimento do autocuidado, bem como a transformação na adoção de hábitos mais seguros com vistas a prevenção das DST, do HIV e da AIDS. O aconselhamento pressupõe a existência de uma postura e atitude profissional que constitui diretrizes para esta prática, quais sejam: o exercício do acolhimento, a escuta ativa, a comunicação competente, a avaliação de riscos e reflexão conjunta sobre alternativas para novos hábitos de prevenção e a orientação sobre aspectos clínicos e do tratamento O processo de aconselhamento exige do enfermeiro a aquisição de conhecimentos, competência e habilidades pertinentes à área para que o cuidado possa ser efetivado de forma a contemplar a

*Enfermeira Coordenadora do Centro de Testagem e Aconselhamento (CTA) da Secretaria Municipal da Saúde de Curitiba. Mestranda em Enfermagem da UFPR. Membro do Grupo de Estudo Multidisciplinar em Saúde do Adulto (GEMSA) da UFPR.

${ }^{* *}$ Professora Adjunta do Departamento de Enfermagem da UFPR. Membro do GEMSA. Doutora em Enfermagem pela UFSC/SC

**Professora Sênior do Programa de Pós-Graduação em Enfermagem da UFPR. Doutora em Enfermagem pela UFSc Coordenadora do Núcleo de Estudos, Pesquisa e Extensão em Cuidado Humano de Enfermagem (NEPECHE) da UFPR. multidimensionalidade de aspectos envolvidos na vivência de cada ser.

PALAVRAS-CHAVE: Aconselhamento; Enfermagem; HIV; AIDS; Cuidado.

\section{INTRODUÇÃO}

O processo de aconselhamento é compreendido como uma relação de ajuda para com o outro, que se concretiza mediante uma postura de acolhimento e amabilidade permeada pelo respeito, para que se possa estabelecer uma comunicação clara e objetiva e uma relação de confiança num momento vivencial atípico, difícil e de muita fragilidade. LABRONICI (2002), salienta que esta relação se instaura mediante a situação de encontro/interação, em face de um momento permeado por uma pluralidade de trocas que propicia a complementaridade. Este processo de ajuda agrega uma série de componentes e se expressa de várias formas com a finalidade de resgatar a integralidade da pessoa, descobrir suas potencialidades, fortalecer sua autonomia e responsabilidade no desenvolvimento do autocuidado e transformação de hábitos.

A ação do aconselhamento está centrada no cliente e no reconhecimento de sua demanda, fundamentada em quem ele é, no que sente, na forma como se percebe, na sua compreensão de mundo e no seu saber. É um processo que exige do profissional o sair de si em direção ao outro, propiciando o encontro/interação e, sobretudo respeito à pessoa como ser único, singular, aliado à aquisição de conhecimentos, competências e 
habilidades para realizar este cuidado. Considero que é de extrema importância para aquele que realiza o aconselhamento a busca do autoconhecimento, uma vez que este induz a uma análise existencial, a uma introspeção, a despir-se de preconceitos e auxilia na retirada das máscaras utilizadas na teatralidade da vida cotidiana, auxiliando a compreender e a aprimorar as interações humanas na busca do veraz sentido do cuidado (LABRONICI, 2002).

O aconselhamento foi implantado na década de 80 pelo Ministério da Saúde, por meio da Coordenação Nacional de DST e AIDS, que o define como:

\begin{abstract}
"Um processo de escuta ativa, individualizado e centrado no cliente. Pressupõe a capacidade de estabelecer uma relação de confiança entre os interlocutores, visando o resgate dos recursos internos do cliente para que ele mesmo tenha possibilidade de reconhecer-se como sujeito de sua própria saúde e transformação. Especialmente no âmbito das DST do HIV e da AIDS, o processo de aconselhamento contém três componentes: Apoio emocional ; Apoio educativo, que trata das trocas de informações sobre DST e HIVIAIDS, suas formas de transmissão, prevenção e tratamento; Avaliação de riscos, que propicia a reflexão sobre os valores, atitudes e condutas, incluindo o planejamento de estratégias e redução de risco" (BRASIL, 2000, p. 22).
\end{abstract}

Esta modalidade de cuidado vem sendo realizada principalmente pelos Centros de Testagem e Aconselhamento (CTA), que são unidades da rede básica de saúde do Sistema Único de Saúdes (SUS), criadas fundamentalmente com o objetivo de estimular a adoção de práticas seguras (prevenção primária), ampliar o acesso ao diagnóstico sorológico para o HIV, e encaminhar as pessoas infectadas pelo vírus para serviços de atenção especializada (prevenção secundária) (Brasil, 2002).

Atualmente, a Coordenação Nacional de DST e AIDS vem fomentando a inserção da prática do aconselhamento acompanhado da testagem sorológica, junto aos diversos profissionais da saúde atuantes nas Unidades Básicas de Saúde (UBS) do SUS que atendem pessoas com DST, HIV e a AIDS.

Em Curitiba, a Secretaria Municipal da Saúde, desde 1999, oferece o aconselhamento e a sorologia para o HIV em suas UBS para todas as gestantes e, a partir de dezembro de 2001 passou a ofertar também nesses serviços, às pessoas que vivenciaram alguma situação de risco para a infecção pelo HIV e àqueles que têm interesse em conhecer seu status sorológico.

Ao refletir sobre a prática do aconselhamento no cenário da AIDS e no meu cotidiano profissional como enfermeira/ coordenadora do CTA de Curitiba onde trabalho há 8 anos, e atualmente como aluna do Mestrado em Enfermagem da Universidade Federal do Paraná (UFPR), descortinei após várias leituras, que os elementos integrantes na ação do aconselhamento estão presentes em todas as dimensões do conhecimento da Enfermagem. Assim, busco neste trabalho inter-relacionar a prática de aconselhamento aos quatro padrões de conhecimento de enfermagem propostos por Carper (1978), bem como onde e como o aconselhamento se alicerça no conjunto de conhecimentos considerados mais valiosos na disciplina de Enfermagem.

As dimensões do conhecimento de Enfermagem englobam quatro padrões fundamentais, a saber: o empírico (ciência de Enfermagem), o estético (a arte da Enfermagem), o conhecimento pessoal (o uso terapêutico do eu) e o ético (o componente do conhecimento moral da Enfermagem) (Carper, 1978; Chinn e Kramer, 1995; Carper, 1978 apud Souza, 2001).

Os padrões de conhecimento não são dimensões autônomas, mas interdependentes e:

"[...] é a interação de todos que confere a harmonia e o respeito às características humanas. 0 conhecimento científico, traduzido em cuidado, é a ponte que possibilita a expressão da criatividade, da empatia e da dimensão da arte, a qual media o uso terapêutico do eu, a compreensão das possibilidades e valores pessoais e o respeito ao ser humano, que engloba a dimensão ética" (SOUZA, 2001, p.30).

Para que o leitor possa melhor apreender a inter-relação do processo de aconselhamento aos padrões de conhecimento de enfermagem propostos por CARPER (1978), torna-se relevante contextualizar o aconselhamento ${ }^{1}$ enquanto cuidado. 


\section{ACONSELHAMENTO: UMA CONEXÃO COM OS PADRÕES DE CARPER}

O aconselhamento pressupõe a existência de uma postura e atitude profissional que constitui diretrizes para esta prática, quais sejam: o exercício do acolhimento, a escuta ativa, a comunicação competente, a avaliação de riscos e reflexão conjunta sobre alternativas para novos hábitos de prevenção e a orientação sobre aspectos clínicos e do tratamento (Brasil, 1999).

Quanto ao exercício do acolhimento ou receptividade e acolhida, os profissionais do CTA consideram que uma atitude receptiva no sentido de "acolher" o cliente é uma das primeiras condições para a realização e sucesso do aconselhamento. É preciso perceber e reconhecer que quando o usuário chega ao serviço traz consigo uma carga considerável de fragilidades e angústias pessoais; dominado pelo medo. Portanto, é necessário que ele se sinta apoiado, acolhido e bem-vindo.

O conceito de escuta ativa ou atitude de escuta necessita ser bem entendido, pois muitas vezes esta ação pode ser substituída por mero caráter informativo visto como instrução, repasse de informação ou orientação informativa de caráter normativo (Brasil, 1999). No ato de aconselhar, torna-se premente perceber e distinguir o que é um momento mais informativo com conteúdos e conhecimentos para a prevenção (conhecimento empírico), de um outro momento específico para a abordagem de vivências, sentimentos e questionamentos da pessoa atendida (conhecimento estético).

"Ainda que partilhem do mesmo intuito (a prevenção e a redução de riscos), a orientação cunhada na "escuta" prioriza o movimento do usuário em individualizar aquelas informações, refletindo-as a

\footnotetext{
${ }^{1}$ Vale ressaltar que no decorrer do texto o conceito de aconselhamento será concebido como uma ação cuidativa, vista multidisciplinarmente no processo de trabalho da saúde.

${ }^{2} \mathrm{~A}$ técnica da escuta ativa perpassa por quatro momentos chamados de: "As quatro chaves mágicas de escutar ativamente" que são: focalizar, aceitar, refletir e estimular. Aprendi esta técnica no Treinamento de Prevenção e Assistência em HIV e AIDS ministrado pela International Health Programs - Western Consortium for Public Health em 1997/1998, e financiado pela Coordenação Estadual de DST e AIDS do Estado do Paraná.

${ }^{3}$ Corporeidade é a expressão do corpo (MERLEAU-PONTY, 1994)
}

partir de suas vivências, sendo estimulado a expor suas reais dificuldades para a adoção de determinadas ações que reduziriam seus riscos. Tal distinção, entretanto, não deve significar uma ruptura entre ambas dimensões (informar e escutar), ao contrário, o ideal é que estejam mais articuladas. Ressalta-se porém, que nenhuma destas etapas pode substituir a outra, muito menos serem confundidas. Precisam ser melhor articuladas" (BRASIL, 1999, p. 59).

Creio que a habilidade de "escutar ativamente"2 é o verdadeiro ato originário da criação, que se expressa no momento da entrega, um estar à disposição do outro buscando perceber a compreensão originária na fala, na linguagem, no corpo que é espaço expressivo, conforme pontua Merleau-Ponty (1994), ou simplesmente no momento que se cala.

O ser humano tem uma necessidade imensa de ser escutado, levado a sério, compreendido e aceito. Entretanto, tem medo de mostrar seu mundo privado, de se expor, retirar suas máscaras, de compartilhar seus segredos, vergonhas ocultas, sonhos desfeitos, esperanças e desejos jamais revelados, pois se sente refém do medo do julgamento dos outros.

\footnotetext{
"Mas, se eu lhe dizer quem sou, você pode não gostar de quem sou, e isso é tudo o que tenho".
}

(POWELL, 1992, p.20)

Tais juízos fazem parte da herança cultural, que sempre condicionou as pessoas a reagir e julgar depreciativamente o comportamento daqueles que não agem conforme os padrões determinados por uma maioria que considera o seu modo de vida como o mais "correto" e mais "normal". Por isto, rotula-se e aplica-se estereótipos através dos quais as pessoas se guiam para o confronto cotidiano com a diferença e o diferente. A isto a Antropologia Social chama de etnocentrismo (ROCHA, 1984; LARAIA, 2001).

A epidemia da AIDS se tornou um terreno fértil para as atitudes etnocêntricas, uma vez que evoca temas polêmicos como corporeidade ${ }^{3}$, sexualidade e morte (BARROS, 2000). De tal sorte que, o profissional que escolhe trabalhar com HIV e a AIDS, e deseja estabelecer uma relação de ajuda, deve mantê-la o mais livre possível de qualquer juízo de valor. Isto permitirá que a outra pessoa atinja um 
ponto em que ela própria reconhecerá que o lugar de julgamento, o centro da responsabilidade, reside dentro de si mesma. O sentido e o valor de sua experiência é algo que depende, em última análise, dela própria e nenhum juízo exterior o pode alterar (ROGERS, 1984).

Neste sentido, é preciso estar duplamente atento, pois além das atitudes etnocêntricas, a formação dos profissionais da área da saúde se alicerça num modelo de racionalidade científica que categoriza a doença como foco central, reduzindo os sujeitos apenas a órgãos doentes (LUZ, 1988). Essa racionalidade torna os seres humanos reféns da possibilidade de estabelecer relações em potencial com os outros, cujo produto já está determinado pelo passado, alicerçado nas fórmulas estatísticas que determinarão sua destinação e suas chances, sem possibilidade de transformação.

Rogers (1984) analisa esta atitude sob a ótica dos estudos de Verplanck, Lindsley, Skinner e Buber e explica que, quando se estabelece em uma relação de ajuda certos tipos de conceitos ou opiniões em relação ao outro, tem-se nesta circunstância, a tendência de confirmá-lo como um objeto mecânico e manipulável, ao ver nisto suas potencialidades, a pessoa tem a tendência para agir de modo a confirmar esta hipótese. Mas se, ao contrário, ao considerar a pessoa um ser em potencial, sem pré moldá-la, reforça-se a pessoa que ela é, com todas as potencialidades existentes, então sua tendência de agir vem ao encontro da confirmação desta segunda hipótese. Neste caso, confirma-o como pessoa viva, capaz de um desenvolvimento interno e criativo.

A técnica de "escutar-ativamente" é uma importante ferramenta do cuidado e exige dedicação, sensibilidade, perseverança, paciência, disposição e disponibilidade do cuidador. Segundo Stefanelli (1993), o ato de escutar transmite ao cliente que ele é aceito, respeitado e tratado como ser humano cuja existência tem grande significação, dando-Ihe a possibilidade de se desenvolver no processo de comunicação, e assim, planejar conjuntamente as ações do seu cuidado emergidas a partir de suas reais necessidades.

A Coordenação Nacional de DST e AIDS publicou em 1999 o resultado de uma avaliação qualitativa das ações de aconselhamento em DST, HIV e AIDS desenvolvidas no âmbito de serviços de saúde selecionados do SUS, e apontou que a "atitude de escuta" foi uma das diretrizes do aconselhamento que se revelou mais problemática e a mais precariamente cumprida. O profissional via de regra, nas entrevistas para o aconselhamento, tinha uma postura de "perguntador" sobre a intimidade do usuário, reproduzindo muitas vezes um cenário de anamnese. Em geral, as respostas e os sentimentos colocados pelos usuários não desencadeavam um processo de reflexão e de diálogo entre ele e o profissional, visando uma orientação satisfatória às necessidades individuais de esclarecimento e apoio emocional. O que se observou foi uma constante repetição de preceitos normativos para a prevenção, ou seja, o caráter normatizador e prescritivo foi a tônica da absoluta maioria dos aconselhamentos (BRASIL, 1999).

A comunicação competente, a adequação da linguagem e a busca de favorecer a compreensão do conteúdo comunicacional devem ser uma preocupação presente na prática do aconselhamento. Há que se ressaltar que, o processo comunicacional não é uma via de mão única, entre o emissor e o receptor, mas um processo em que:

"1) o receptor não é "receptáculo" passivo de mensagem, mas sujeito ativo de reconstrução interpretativa do conteúdo informacional; 2) os "ruídos" que comprometem a apreensão da mensagem não se limitam à não clareza da linguagem, mas também dizem respeito a não partilha dos significados culturais vinculados às vivências dos indivíduos a quem se destina a mensagem; 3) a relação comunicacional, não se baseia numa relação estanque entre "emissorreceptor" mas numa troca (conflitiva ou não) entre ambos, em que "emissor" se torna "receptor" e viceversa” (HABERMAS apud BRASIL, 1999, p.27).

Torna-se importante distinguir entre repasse de informação e comunicação, porquanto a comunicação diz respeito à possibilidade do diálogo, do encontro e de reciprocidade.

A avaliação de riscos e reflexão conjunta sobre alternativas para novos hábitos precisa ser centrada na vivência e na real expectativa da pessoa. Desta forma, é fundamental investir neste aspecto, estimulando os profissionais a desenvolver uma dinâmica pessoal de abordagem, mas tendo como apoio às bases técnicas para tal, visto que a orientação para a prevenção não pode estar 
centrada numa perspectiva meramente normativa e de controle, pois já se mostrou de baixa eficácia. Ela precisa ser traçada dentro de um campo de parceria e de troca, refletindo em conjunto os riscos e estratégias para a prevenção. A idéia é de personalizar o atendimento e a informação geral e científica, para adequá-las às características e vivências do próprio usuário (BRASIL, 1999). Para tal, as vivências, as falas e as percepções dessas pessoas precisam ser tomadas como matériaprima para elaboração de planos de ação, visando a redução de riscos para a infecção pelo HIV e outras DST.

Sem dúvida alguma que a carga emocional decorrente das diversas reações e da variedade de situações que os profissionais precisam manejar é muito grande, vez que a pessoa traz em seu corpo as angústias, medos, fantasmas e receios, decorrentes do imaginário da AIDS e que acabam desencadeando atitudes de ordem afetiva e emocional muitas vezes inesperadas e desesperadas. Por considerar estas questões de difícil manejo, há que se propiciar espaços onde os profissionais aconselhadores possam falar de suas fragilidades, problemas, receios e dúvidas (Feltham e Savard, 2000), com o intuito de fortalecer as pessoas que cuidam das outras a se tornarem menos ingênuas e mais inteiras, ao também focalizarem a sua dimensão subjetiva na prática do aconselhamento.

A capacidade de sentir e perceber as emoções que insurgem no processo do aconselhamento de forma saudável e madura e o discernimento do que é meu e do que é do outro, promovem o compartilhamento e a troca de experiências através da complementaridade do ver e tocar com o ouvir e sentir. Deste momento concebido como singular e único, é que emerge a arte de cuidar da Enfermagem, levando a construção de um novo significado vivenciado pelo crescimento e transformação de ambos os atores, que é o autêntico alicerce do cuidado.

A abordagem sobre as temáticas implícitas nos aspectos clínicos e de tratamento precisa ser ajustada com as situações específicas, ou seja, a real necessidade vivenciada pelo cliente durante o atendimento, e a capacidade de compreensão e conhecimento do mesmo sobre o tema. Uma vez que o aconselhamento "trata-se de uma relação interpessoal, face a face, orientado pelo apoio de ordem emocional e transmissão de conteúdos informativos e preventivos de maneira a serem apropriados e gerenciados por cada cliente segundo suas vivências e singularidade" (Brasil, 1999, p.10).

Assim, dimensionar o que e como informar se torna imperativo, de tal sorte que o conteúdo informativo não se perca em discursos generalizantes e impessoais. É preciso que o cliente se aproprie das informações e que as transforme em reflexões voltadas para a tomada de decisões e atitudes, tornando-se sujeito no processo de prevenção e de cuidado de si (BRASIL, 1999). Contudo, é importante refletir de que forma e em que medida essas informações deverão ser transmitidas. Para tanto é preciso que o enfermeiro utilize a sensibilidade, tato, intuição e conhecimento para avaliar caso a caso evitando "subestimar" ou "superestimar" as possibilidades da pessoa. Neste sentido, a avaliação ajudará o outro a buscar o equilíbrio e garantirá a autêntica participação do cliente no cuidado de si.

\section{CONHECIMENTO EMPÍRICO: A CIÊNCIA DE ENFERMAGEM}

É a dimensão do mundo empírico no qual o conhecimento encontra-se sistematicamente organizado em leis e teorias com o objetivo de descrever, explicar e prever fenômenos de interesse. É construído baseado em um modelo formulado discursivamente e publicamente verificável (CARPER, 1978).

A visão da ciência tradicional, que legitima o conhecimento empírico como a expressão da verdade, vem sendo aos poucos desbancada, uma vez que não consegue responder a grande diversidade dos aspectos humanos. Segundo Chinn e Kramer (1995), as teorias de Enfermagem possuem características que são consistentes com os ideais da ciência tradicional. Todavia, sendo a Enfermagem uma disciplina voltada ao cuidado humano, no qual o ideário pressupõe uma visão integral do ser, lança mão de outros padrões de conhecimento que assumem um status de grande significância, remetendo, assim, o conhecimento da profissão para além do limite da ciência tradicional.

No âmbito das DST, do HIV e da AIDS, um 
dos pressupostos no processo de aconselhamento é a troca de informações sobre essas patologias, suas formas de transmissão, prevenção e tratamento, com vistas à educação em saúde (Brasil, 1999; 2000). Logo, o enfermeiro que realiza o aconselhamento precisa se apropriar do conhecimento científico relacionado aos modos de transmissão do HIV, a evolução da doença, as medidas de precauções universais e as informações sobre a cultura, etnicidade, nível sócioeconômico, sexo, sexualidade e dados epidemiológicos que demarcam o trilhar da epidemia da AIDS.

A aquisição e atualização de tais conhecimentos são necessárias para esclarecer dúvidas e colaborar na desconstrução de crenças e mitos muito presentes no ideário coletivo da AIDS. Segundo autores como Berer (1997), Bastos (1996), Mann et al. (1993), Grmek (1989), um dos fatores importantes na difusão do HIV recai sobre a ignorância. A falta de informações associada a concepções errôneas quanto à sexualidade, uso de drogas e vias de transmissão do HIV, cria a necessidade de se eleger espaços para a discussão desse tema sem que seja tratado de forma preconceituosa e parcial.

No entanto, é essencial registrar que o modelo de intervenção que focaliza apenas o repasse de informação mostra-se insuficiente, quando se busca mudanças de atitudes e comportamentos com vistas à prevenção da infecção pelo HIV ou adoecer de AIDS. Neste sentido, é pertinente que se contemplem novos entendimentos que perpassam pelas questões subjetivas no conviver com HIV e a AIDS, uma vez que é uma doença que possui uma pluralidade de significados, e que, apesar de passados mais de 20 anos de sua descoberta, ainda carrega as quimeras construídas no imaginário social.

Cônscia de que as doenças, e principalmente a AIDS, adquirem tantos e variados significados, uma vez que passam a representar os temores mais profundos, e que verberam aqueles que são atingidos por ela, é possível e necessário, transformar estes significados, buscando novas formas de interpretação e agir no cuidado prestado pelo enfermeiro. Assim, o conhecimento estético acrescenta discernimentos importantes que vêm complementar a ação cuidativa no processo de aconselhamento, ao trazer no momento da cena as vivências, experiências, valores, idéias, crenças, necessidades emocionais e físicas das pessoas atingidas direta ou indiretamente pela epidemia do HIV e da AIDS.

\section{CONHECIMENTO ESTÉTICO: A ARTE DE CUIDAR}

O processo do conhecimento estético em enfermagem é "[...] a compreensão do significado numa expressão subjetiva, única e particular que pode ser chamada de arte/ato" (CHINN e KRAMER, 1995, p.30). Há que se diferenciar no processo estético o ato de reconhecer e o de perceber. 0 reconhecimento se presta para identificar e atinge seus objetivos quando atribui um rótulo baseado em um estereótipo ou em alguma classificação anteriormente definida (DEWEY apud CARPER, 1978). A percepção que é a real experiência estética vai além do reconhecimento, pois inclui o ato genuíno da criação que leva a conhecer e expressar os sentimentos de forma singular, única, de sentir e experienciar o significado do momento vivido e a capacidade de abstrair, observar e transformar uma determinada experiência em algo que, embora ainda não existente, é possível (CARPER, 1978; CHINN e KRAMER, 1995).

A dimensão estética na arte de cuidar "[...] é uma forma de expressão cultural, de comunicação e, dessa forma, expressa sentimento" (Waldow, 1998, p.163). Segundo Paterson e Zderad apud Praeger e Hogarth (1993), a experiência subjetiva dos seres humanos é tão válida quanto a experiência objetiva que pode ser medida. Entendendo que o ato de cuidar pressupõe um encontro/interação, momento que delineia uma relação especial entre duas pessoas e ocorre quando elas atingem uma verdadeira comunhão ou comunicação ao compartilharem sua existência, a forma como esta comunicação construir-se-á, é que resultará no sucesso ou insucesso do cuidado prestado e da resposta emitida pela pessoa cuidada. No verdadeiro encontro/interação a preocupação das pessoas não está na solução de problemas, mas na comunhão e no ato de partilhar emoções e sentimentos (POWELL, 1992). Para o autor, todo crescimento, lesão e repressão, assim como a cura das pessoas, resulta do 
relacionamento com os outros.

Mitchell apud Carper (1978), observa que há fortes evidências que a qualidade dos contatos interpessoais tenha influência sobre uma pessoa que ficou doente e como ela enfrenta este problema. Neste sentido, se o enfermeiro busca êxito no cuidado que está oferecendo ao outro, ele precisa refletir sobre alguns aspectos relevantes que influenciam o processo interpessoal:

"1) Quase todos os prazeres e sofrimentos da vida estão profundamente envolvidos com emoções. 2) A maior parte da conduta humana é resultado de forças emocionais (embora sejamos todos tentados a passar por puros intelectos, e a explicar nossas preferências e ações através de bases racionais, objetivas). 3) A maior parte dos conflitos interpessoais resulta de tensões emocionais (por exemplo, raiva, ciúme, frustração, etc.) e a maioria dos encontros interpessoais são alcançados através de algum tipo de comunhão emocional (por exemplo, empatia, ternura, sentimentos de afeição e atração)" (POWELL, 1992, p. 87 e 89).

Assim, para a compreensão dos fatores supracitados que permeiam o processo cuidativo, torna-se imperativo o modo como o enfermeiro utiliza sua criatividade e habilidade - a arte do cuidar - na busca e provisão de cuidados efetivos, satisfatórios e gratificantes para ambos os atores envolvidos.

Avalio que na prática cotidiana do aconselhamento, os aspectos do conhecimento estético são de suma importância para a consecução efetiva deste processo e merece ser compreendido na vivência experiencial do mesmo.

Ressalte-se que o aconselhamento não é o feito de dar conselhos normatizadores de conduta ou aplicação de questionário de forma mecânica, como um check-list dos aspectos e acontecimentos da vida íntima da pessoa, que será de muito pouca valia para aquele momento (BRASIL, 1999). O produto do aconselhamento é um construto binário, no qual o êxito dependerá da relação estabelecida entre enfermeiro e cliente, motivo pelo qual tornase fundamental investir neste aspecto, estimulando cada profissional a desenvolver uma concepção estética de abordagem, tendo como apoio às bases técnicas para a sua realização.
O campo do conhecimento pessoal compreende a busca interior de tornar-se um todo consciente de si, capaz de se reconhecer em sua importância e totalidade (CARPER, 1978; CHINN e KRAMER, 1995).

Powell (1992) acredita que é no compartilhar o seu mundo que a pessoa se conhece, ou seja, ela só pode se reconhecer e experienciar a plenitude da vida através do contato com a outra pessoa, visto que a existência se dá num processo de coexistência (existir com o outro).

"É o outro que me dá referência de que nem sou o anão dos meus pesadelos nem o gigante dos meus sonhos"

(Autor desconhecido)

Neste contexto, entendendo o ato de cuidar como um encontro/interação do enfermeiro com o cliente conforme enfatiza Labronici(1999, 2002), que ao ser influenciado pelos sentimentos surgidos pela antecipação do mesmo, como salientam Praeger e Hogarth (1993), torna-se uma grande aventura em que há descobertas contínuas e cada vez mais profundas, a partir do momento que ambos permitem se desvelar. É uma experiência genuína, de abertura para si, para o outro e para o mundo, que possibilita a ampliação de horizontes, aumenta a atenção para o cuidado, aprofunda os sentimentos e oferece sentido à vida.

Diferentemente do conhecimento empírico e ético, o pessoal não pode nem consegue ser comunicado ou escrito, ele é vivenciado. Segundo Powell (1992), as pessoas só conseguem saber a seu respeito, aquilo que conseguem expressar aos outros.

Quando o enfermeiro se mostra aberto ao sentido da experiência para o outro, consegue captar de modo intuitivo, o fenômeno de uma situação de Enfermagem. Para facilitar a própria receptividade e para que isto ocorra, PATTERSON e ZDERAD, apud PRAEGER e HOGARTH (1993, p. 247) sugerem que:

"se vá à situação de enfermagem sem quaisquer noções, preconceitos, tentando evitar expectativas, rótulos e julgamentos. É importante que, inicialmente, conheçamos os preconceitos próprios, conscientizando-nos de nossas tendências filosóficas e teóricas (...). Todas essas atividades exigem um esforço consciente por parte da enfermeira, na direção da auto-percepção. Agindo assim, no entanto, as 
enfermeiras podem estar receptivas a todas as situações de enfermagem, e serão mais capazes de captar, de modo intuitivo, as nuances sutis, envolvidas na interação humana"

Considerando que a angústia é parte integrante da existência humana, ligada aos conflitos individuais ou coletivos, o espectro assustador da epidemia da aids não afeta apenas àqueles que são portadores da doença, mas toda a coletividade que convive com ela (LENT e VALLE, 1997). Se, está se falando de profissionais aconselhadores que estão engajados numa relação de ajuda, esforço-me em reafirmar, a necessidade de garantir uma postura de desvelo frente a eles, permitindo a expressão de suas angústias, medos e inseguranças, assegurando uma verdadeira integração da experiência ligada à proximidade da morte, originada pela AIDS.

Acredito que somente através da preocupação, elaboração e lapidação face à experiência genuína dos significados que a epidemia da AIDS faz insurgir, é que se torna possível oferecer às pessoas acometidas uma melhor qualidade do cuidado, dos serviços e da vida, e quiçá essa busca de entendimento pessoal possa substituir o espectro distorcido e preconceituoso da epidemia, pela solidariedade.

\section{CONHECIMENTOÉTICO}

O padrão de conhecimento ético segundo Carper (1978), Chinn e Kramer (1995), está relacionado a obrigação ou ao que deve ser feito ou realizado. Ele vai além das normas ou códigos de ética da disciplina, pois envolve julgamentos realizados a todo o momento sobre o certo e errado, sobre o que deveria ser feito, sobre escolhas morais e responsabilidades. Eles postulam a necessidade de compreender as diferentes posições filosóficas sobre as quais residem as decisões éticas em relação ao que é bom, o que deveria ser desejado e o que é certo na Enfermagem. Neste sentido os autores lançam um olhar crítico sobre fatores empiricamente discerníveis, que são expressos pelos princípios, códigos de ética e sobre como as questões éticas têm sido examinadas, e referem que somente a ótica das normas, teorias e leis não estão dando conta da complexidade e pluralidade da sociedade pós-moderna, motivo pelo qual necessitam ser melhor discutidas.

É fato que a epidemia da AIDS é um dos grandes problemas contemporâneos, de ordem mundial, e que ao irromper trouxe à tona várias questões de natureza ética requerendo de todos reflexões acerca do comportamento e atitudes e, particularmente, no que tange a conduta dos profissionais da área da saúde, preceituando abordagens sob o ponto de vista ético das situações novas trazidas no dia-a-dia da doença. Ressalte-se que o conceito de ética aqui utilizado descrito por Dâmaso (1995) significa ética enquanto prática do caráter, dos costumes, dos hábitos, da conduta e da solidariedade.

A grande questão ética da AIDS surgiu quando o mundo experimentou em 1980, o recrudescimento de posturas recheadas pela ignorância e discriminação contra grupos sociais identificados como susceptíveis em maior grau à aquisição da doença, quais sejam: os homens com práticas homoeróticas ${ }^{4}$, os usuários de drogas injetáveis e as prostitutas. Aqueles que defendiam a hostilidade contra tais grupos acreditavam que agindo assim, conseguiriam aumentar a sua segregação e, por conseqüência, obter a circunscrição da doença a faixas controláveis (VENTURA DA SILVA, 1995).

$\mathrm{Na}$ verdade tais posturas traduziam tão somente a intolerância experimentada em face de comportamentos que se consideravam indesejáveis. Em outras palavras, o que se queria combater, não era a doença, e sim o comportamento. Em função de uma lógica perversa, advinda do preconceito e da ignorância, e associada a incurabilidade da doença, acabaram determinando à pessoa com HIV ou AIDS uma condenação não só pela morte biológica, natural e destinada a todos os seres humanos, mas com muito mais rapidez, que é a morte civil $^{5}$, impedindoa de exercer plenamente todos os seus direitos de

\footnotetext{
${ }^{4}$ Este termo designa o padrão de interesse erótico ou sexual, por uma pessoa do mesmo sexo. (GOLDENSO e ANDERSAN, 1989)

${ }^{5} \mathrm{~A}$ descrição do termo morte civil foi descrita por Décio Manuel onde diz que "É a morte fictícia imposta a pessoa em conseqüência de pena, privando-a da liberdade e do exercício pleno de todos os seus direitos de cidadão. A pena da morte civil foi abolida do Brasil ainda quando era colônia" Citação feita no BOLETIM AÇÃO ANTI-AIDS, n. 17, artigo apud GRUPO PELA VIDA (1993).
} 
cidadã. A AIDS deixa de ser uma doença para ser uma pena aplicada aos julgados criminosos morais (grupo pela vidda, 1993).

Foi a Constituição Federal de 1998 que trouxe alguns avanços de ordem jurídica, impondo às autoridades e toda a sociedade, o espírito de solidariedade. É textual quando elenca no seu art. $3^{\circ}$ como fundamentos da nação a "construção de uma sociedade livre, justa e solidária", obrigando a promoção do bem de todos, sem preconceitos de origem, etnia, sexo, cor, idade e quaisquer outras formas de discriminação, garantindo a igualdade de todos perante a lei (grupo pela vidda, 1993, p.11). Desde então, muitos avanços foram conquistados graças, principalmente, a organização política dos grupos acometidos pela doença.

Termino parafraseando DÂMASO (1993) ao relatar que, ainda que o vertiginoso avanço da epidemia tenha rompido as fronteiras dos grupos de risco, é preciso estar atento e não subestimar o simbólico que estreita a AIDS à morte e à sexualidade, pois estas são, na verdade, o próprio solo de constituição da ética e da moralidade.

\section{IDÉIAS CONCLUSIVAS}

O objetivo deste artigo foi refletir sobre a prática do aconselhamento à guisa dos quatro padrões de conhecimento da Enfermagem. Acredito que através dos achados teóricos e de minha prática profissional e pessoal, consegui articular conhecimentos da disciplina de Enfermagem, com os pressupostos de uma ação que, a princípio, não é legitimada no âmbito da profissão, posto que o aconselhamento é visto como uma ação de responsabilidade da Psicologia. Contudo, como pessoa e profissional enfermeira, apaixonada pelo aconselhamento acredito que pude cumprir com meu objetivo, e assim colaborar com os colegas de profissão, tornando visível a possibilidade de se fazer conhecer o aconselhamento como uma ação cuidativa de grande significado para aquele que cuida e aquele que é cuidado. Tal campo de ação, proficiente para a profissão, clama por pessoas sensíveis e interessadas em colaborar de forma solidária. Aprendi nessa minha caminhada, que se iniciou há oito anos no CTA, a respeitar e validar a importância da diferença e do diferente. Essas vivências me permitiram lançar novos olhares às múltiplas realidades existentes que permeiam o cotidiano da AIDS, e me ajudaram a substituir a lente da distorção e do preconceito pela da solidariedade.

ABSTRACT: A thought-provoking article which aims to interrelate the practice of the counseling process to the four patterns of nursing knowledge (empirical, esthetic, personal and ethical) proposed by CARPER (1978). The counseling process on STD, HIV and AIDS entails a relationship of help and care with the other objectifying to recover his/her wholeness, to find out his/her potentialities, to strengthen his/her autonomy and responsibility undertaking self-care, and effect the adoption of safer habits in order to prevent STD, HIV and AIDS. Counseling implies the existence of a professional posture and attitude, which take up the guidelines for this practice, such as: welcoming exercise, active listening, competent communication, risk assessment and joint pondering over the alternatives towards new preventive habits besides guidance on clinical and treatment aspects. The counseling process demands nurses to acquire proper knowledge, competence and abilities so that care can be provided in such a way to apprehend the multidimensional aspects in the lived experience of each human being.

KEY WORDS: Counseling; Nursing; HIV; AIDS; Care.

\section{REFERÊNCIAS}

BARROS, E. P. Aids e diversidade sócio cultural. Congresso virtual, 2000. Endereço eletrônico: www.naya.org.ar/congresso 2000/ ponenciais/Edir Pina de Barros.htm

BASTOS, F. I. Ruína e reconstrução: AIDS e drogas injetáveis na cena contemporânea. Rio de Janeiro. Relume-Dumará: ABIA: IMS/UERJ, 1996.

BERER, M. Mulheres e HIVIAIDS: um livro sobre recursos internacionais; informação, atividades e materiais relativos às mulheres HIVIAIDS, saúde reprodutiva e relações sexuais. São Paulo: Brasiliense, 1997. 
BRASIL, Ministério da Saúde. Aconselhamento: um desafio para a prática integral em saúde avaliação das ações. Brasília. Secretaria de Políticas Públicas. Coordenação Nacional de DST, HIV e Aids 1999.

Aconselhamento em DST, HIV e AIDS: diretrizes e procedimentos básicos. Brasília: $4^{\mathrm{a}}$ ed., 2000.

Vigilância do HIV no Brasil: novas diretrizes. Brasília, 2002.

CARPER, B .A. Fundamental patterns of knowing in nursing. Advanced Nursing Science, v.1, n.1, p. $13-23,1978$.

CHINN, P. \& KRAMER, M. T. Theory and nursing: a sistematic approach. St. Louis, Morby, $4^{\circ}$ ed., 1995

DÂMASO, R. AID'Ética -A AIDS da Ética. In: CZERESNIA, D. et al. (Org.). AIDS: ética, medicina e bioética. São Paulo - Rio de Janeiro: HUCITEC / ABRASCO, 1995.

FELTHAM, R. \& SAVARD, S. Reflexões sobre a contratransferência de interlocutores e de voluntários que trabalham com pessoas vivendo com HIV ou aids. Boletim da Rede de Direitos Humanos em HIVIAids. Brasília, ano 4, edição especial - 2000.

GOLDENSON, R. M.; ANDERSAN, K. N. Dicionário de sexo. São Paulo: Ática, 1989.

GRMEK, M.D. Histoire du Sida. Paris: Payot, 1989.

GRUPO PELA VIDDA. Direitos das pessoas vivendo com HIV e Aids. Rio de Janeiro: Fundação Ford e Sociedade Viva Cazuza, 1993.

LABRONICI, L. M. Corporeidade no cenário da clínica ortopédica. Porto Alegre: Edições EST, 1999.

LABRONICI, L. M. Eros propiciando a compreensão da sexualidade das enfermeiras. Tese (Doutorado em Enfermagem) - área de concentração: Filosofia - Pós-Graduação em Enfermagem, Florianópolis, 2002.

LARAIA, R. B. Cultura: um conceito antropológico. Rio de Janeiro: Jorge Zahar Ed., 14 ed., 2001.

LENT, C. F. ; VALLE, A. Pontes - aids e assistência. Rio de Janeiro: Projeto PonteS / Banco de Horas / IDACV, 1997.

LUZ, M. T. Natural, racional, social: razões médicas e racionalidade científica moderna. Rio de Janeiro: Campus, 1988.

MANN, J.; TARANTOLA, D. J. M.; NETTER, T. W. (Org.). A AIDS no mundo. Rio de Janeiro: Relume - Dumará. ABIA: IMS, UERJ, 1993.

MERLEAU-PONTY, M. Fenomenologia da percepção. São Paulo: Martins Fontes, 1994

POWELL, S. J. J. Porque tenho medo de dizer que sou. Belo Horizonte: Crescer, 1992.

PRAEGER, S. G. \& HOGARTH, C.R. Josephine E. Paterson e Loretta T. Zderad. In: GEORGE, J. B. et all. Teorias de enfermagem: fundamentos para a prática profissional. Porto Alegre: Artes médicas, 1993.

ROCHA, E. O que é etnocentrismo. Brasília: Brasiliense, 1984.

ROGERS, C. Tornar-se pessoa. São Paulo: Martins Fontes, 1984.

SOUZA, M. F. As teorias de Enfermagem e suas Influências nos processos cuidativos. In: CIANCIARULLO, T. I.; GUALDA, D. M. R.; MELEIRO, M. M. ; ANABUKI, M. H. (Org.). Sistema de assistência de enfermagem: evolução e tendências. São Paulo: ÍCONE, 2001.

STEFANELLI, M.C. Comunicação com o paciente: teoria e ensino. São Paulo: Robe Editorial., 1993.

VENTURA DA SILVA, M. Legislação sobre DST \& AIDS no Brasil. Ministério da Saúde. Secretaria de Assistência à Saúde. Coordenação Geral do PN 
DST/AIDS. Brasília: Coordenação geral do PN DST/ AIDS. 1995.

WALDOW, V. R. Cuidado humano: o resgate necessário. Porto Alegre: Sagra Luzzato, 1998.

ENDEREÇO DOSAUTORES: R. Schiller, 1140 - ap. 24E Alto da XV - Curitiba / PR 80040-160

almeidacassia@ig.com.br 